\title{
Ablation of the Murine $\alpha$ Myosin Heavy Chain Gene Leads to Dosage Effects and Functional Deficits in the Heart
}

\author{
W. Keith Jones, ${ }^{\star}$ Ingrid L. Grupp, ${ }^{\ddagger}$ Thomas Doetschman, ${ }^{\S}$ Gunter Grupp, Hanna Osinska, ${ }^{*}$ Timothy E. Hewett, ${ }^{\star}$ Greg Boivin, \\ James Gulick, ${ }^{*}$ Willie A. Ng, ${ }^{*}$ and Jeffrey Robbins* \\ *Division of Molecular Cardiovascular Biology, Children's Hospital Research Foundation, Cincinnati, Ohio 45229-3039; and Department \\ of ${ }^{\ddagger}$ Pharmacology and Cell Biophysics; Department of ${ }^{\S}$ Molecular Genetics, Microbiology and Biochemistry; and Department of \\ "Molecular and Cellular Physiology, "University of Cincinnati College of Medicine, Cincinnati, Ohio 45267
}

\begin{abstract}
The $\alpha$-myosin heavy chain ( $\alpha$-MyHC) is the major contractile protein expressed in the myocardium of adult mice. We have produced mice carrying a null mutation of $\alpha-M y H C$ by homologous recombination in murine ES cells. Homozygous null animals die between 11 and $12 \mathrm{~d}$ in utero of gross heart defects, while $\alpha-M y H C^{+l-}$ heterozygotes survive and appear externally normal. The presence of a single functional $\alpha-\mathrm{MyHC}^{+}$allele in heterozygous animals results in reduced levels of the transcript and protein as well as fibrosis and alterations in sarcomeric structure. Examination of heart function using a working heart preparation revealed severe impairment of both contractility and relaxation in a subset of the $\alpha-\mathrm{MyHC}^{+/-}$animals. Thus, two $\alpha-\mathrm{MyHC}^{+}$alleles are necessary for normal cardiac development, and hemizygosity for the normal allele can result in altered cardiac function. (J. Clin. Invest. 1996. 98:1906-1917.) Key words: embryonic stem cells $\bullet$ gene targeting $\bullet$ myosin $\bullet$ left ventricular function $\bullet$ gene dosage $\bullet$ myofibrils
\end{abstract}

\section{Introduction}

The major component of the mammalian heart's contractile apparatus, the myosin heavy chain $(\mathrm{MyHC})^{1}$ exists as three

Address correspondence to Jeffrey Robbins, Ph.D., Division of Cardiovascular Molecular Biology, Children's Hospital Research Foundation, 3333 Burnet Avenue, Cincinnati, OH 45229-3039. Phone: 513559-8098; FAX: 513-475-3852; E-mail: Teachdna@aol.com or Jeff.Rob bins@chmcc.org

Received for publication 22 December 1995 and accepted in revised form 16 August 1996.

1. Abbreviations used in this paper: $+d P / d t$, the first derivative of the increase in left ventricular systolic pressure with respect to time, $-d P / d t$, the first derivative of the decrease in left ventricular systolic pressure with respect to time, a measure of relaxation; ANF, atrial natriuretic factor; BNP, brain natriuretic factor; ES, embryonic stem (cells); FHC, familial hypertrophic cardiomyopathy; IFM, indirect flight muscles; IVP, intraventricular pressure; MAP, mean aortic pressure; MLC, myosin light chain (MLC2v indicates the ventricular isoform of the regulatory light chain and MLC2a, the atrial isoform. MLC1v indicates the ventricular isoform of the essential light chain, and MLC1a the atrial isoform); $\mathrm{MyHC}$, myosin heavy chain; $\mathrm{P}_{2}$ partial pressure of carbon dioxide; $\mathrm{PO}_{2}$, partial pressure of oxygen; PTU, propylthiouracil; $\mathrm{RT}_{1 / 2}$, half-time of relaxation; $\mathrm{SV}$, stroke volume; TPP, time to peak pressure.

J. Clin. Invest.

(C) The American Society for Clinical Investigation, Inc. 0021-9738/96/10/1906/12 \$2.00

Volume 98, Number 8, October 1996, 1906-1917 distinct isoforms, $\mathrm{V}_{1}, \mathrm{~V}_{2}$ and $\mathrm{V}_{3}$. The $\mathrm{V}_{1}$ and $\mathrm{V}_{3}$ isoforms are homodimers of the polypeptides encoded by $\alpha-M y H C$ and $\beta$ - $M y H C$, respectively: the $\mathrm{V}_{2}$ isoform is the heterodimer. The relative amounts of the three isoforms vary depending upon the developmental stage, the cardiac compartment, the animal, and the physiological status of the heart. In the mouse, during gestation, $\alpha-M y H C$ is expressed in the developing atria and $\beta-M y H C$ is transcribed in the ventricles. At, or immediately before birth, $\beta-M y H C$ is silenced and $\alpha-M y H C$ is transcribed in both the atria and ventricles $(1,2)$. This antithetic relationship may be mechanistically linked (3). Thus, although the embryonic/fetal ventricle is mostly $\mathrm{V}_{3}, \mathrm{~V}_{1}$ is the primary isoform expressed in both compartments of the adult murine heart.

The MyHC is the molecular motor which underlies the heart's function as a pump. It has been shown that mutations in the human $\beta-M y H C\left(\mathrm{~V}_{3}\right.$ is the predominant isoform in the human ventricle) are associated with Familial Hypertrophic Cardiomyopathy (FHC), an inherited autosomal dominant disease which results in sarcomeric disarray, heart failure, and sudden cardiac death (4). The genetic dominance of the disease is consistent with either a reduction in the amount of the normal protein in the sarcomere, or the incorporation of an abnormal "dominant negative" $\mathrm{V}_{3}$. Experimental evidence supports the hypothesis that dominant negative $\beta-M y H C$ mutations affect muscle structure and function: skeletal muscle fibers expressing $\beta$ - $M y H C$ missense mutations associated with FHC have abnormal contractile properties (5); and in cell culture experiments, heterologous expression of specific mutant MyHCs disrupts actin-myosin interaction and interferes with sarcomere assembly (6). Furthermore, a mouse model created by gene targeting, which carries a documented FHC mutation in $\alpha-M y H C$, shows pathologies that are in some ways characteristic of FHC, as well as alterations in cardiac function (7). There are no experimental data in mammals bearing upon the possibility that disease may result from reduction of $\mathrm{MyHC}$ protein as might result from heterozygosity for a null $\beta-M y H C$ allele.

The details of myofibril assembly in vivo have been studied extensively by genetic means in both Drosophila melanogaster and Caenorhabditis elegans. In C. elegans, dominant negative mutations that effect function and sarcomere assembly in the muscles of the body wall have been used to dissect myosin functional domains. In contrast, animals heterozygous for a null MyHC mutation are functionally normal, and capable of producing well organized thick filaments. Extrapolation of these results to the mammalian heart must be tempered by the fact that a second MyHC is known to be expressed in C. elegans body wall muscles. Finally, it is difficult to interpret the results with respect to sarcomere assembly because of differences between the sarcomeric organization of $C$. elegans and vertebrates. 
The sarcomeric proteins of the Drosophila indirect flight muscle (IFM) have been amenable to genetic analysis because mutations which effect IFM-specific isoforms may be recovered by their affect upon flight. The insect's IFM are longitudinally oriented muscles with highly ordered myofibrils and are ideally suited for investigating the ultrastructural consequences of mutant sarcomeric genes. In Drosophila melanogaster there is a single gene which generates, by alternative splicing, MyHC isoforms specific to the various muscles. Flies heterozygous for $M H C 36 B^{I f m 2(2)}$, a null MyHC allele, have a $50 \%$ reduction of MyHC protein and the IFM are dysfunctional $(8,9)$. These muscles have a series of defects in sarcomeric and myofibrillar organization reflecting loss of thick filament structures. Muscles from animals heterozygous for an IFM-specific actin null allele, Act $88 F^{K M 88}$, possess dysfunctional IFMs with ultrastructural defects involving the thin filaments. Thus, in Drosophila, animals heterozygous for null mutations affecting $\mathrm{MyHC}$ or actin have severe dysfunction of the flight muscle associated with a gene dosage effect and aberrant sarcomere assembly. Interestingly, animals doubly heterozy-

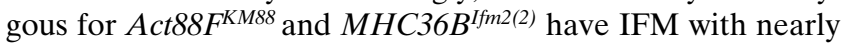
normal function and structure (8). This suggests that the defects noted in the singly heterozygous animals are a consequence of the altered ratio of actin and myosin rather than the absolute reduction of either.

These results served as the rationale for our study. We wished to determine whether a null mutation of the cardiac MyHC would result in a gene dosage effect with consequences for the mammalian heart or whether the genetic apparatus could compensate for the deficit by up-regulating the remaining allele or even another $M y H C$ gene (e.g., $\beta$ - $M y H C$ ). Here we show that ablation of $\alpha-M y H C$ by homologous recombination in ES cells results in a gene dosage effect with consequences for both cardiac myofibrillar structure and cardiac function.

\section{Methods}

Construction of the targeting vector and Southern analyses. The targeting construct was made using isogenic DNA cloned in our laboratory. Two DNA fragments corresponding to the short and long arms of the targeting construct were isolated. The short arm consisted of a $3.2 \mathrm{~kb}$ BglII-EcoRI fragment which corresponds to a portion of the $\beta-M y H C \rightarrow \alpha-M y H C$ intergenic region. The long arm consisted of an $8.5 \mathrm{~kb}$ BsaI-BamHI fragment, which extends from the end of the third exon of the $\alpha-M y H C$ gene toward the $3^{\prime}$ end of the locus. These two fragments were cloned into the BamHI and EcoRI sites, respectively, of the MJK-KO vector (Kern, M., Medical University of South Carolina, Columbia, SC, personal communication). Clones were selected that contained inserts such that the relative genomic orientations were retained, resulting in a deletion of approximately $2-\mathrm{kb}$ of the $\alpha-M y H C$ gene. The deleted region is replaced by the $p g k \bullet$ neo $\bullet$ polyA cassette, which normally resides within the plasmid. The deleted sequences include the $5^{\prime}$ untranslated region, the start sites of transcription and translation and the first 3 exons of the $\alpha-M y H C$ gene. The DNA probe used to detect the targeted $\alpha-M y H C$ allele was generated by PCR using two oligonucleotides positioned to produce an 87 -bp product. The sequences of these oligonucleotides are; $\left(5^{\prime}-\right.$ TCACACAAGGGTCTCCACCCACC- ${ }^{\prime}$ ), and (5'-GCTCTGGGGAGGCCAGCATTGTGAG-3'). The probe lies entirely external and $5^{\prime}$ of the targeting construct and was labeled by random priming. The probe was hybridized to Southern blots in $5 \times$ SSC, $1 \%$ SDS, $5 \times$ Denhardt's, $200 \mu \mathrm{g} / \mathrm{ml}$ sheared salmon sperm DNA. Post hybridization washes were: 3 times for $5 \mathrm{~min}$ in $0.5 \times \mathrm{SSC}, 1 \% \mathrm{SDS}$ at $60^{\circ} \mathrm{C}$, and 1 time for $15 \mathrm{~min}$ in $0.2 \times \mathrm{SSC}, 1 \% \mathrm{SDS}$ at $60^{\circ} \mathrm{C}$. The probe hybridizes to the $6.5-\mathrm{kb}$ StuI fragment diagnostic for the wild type $\alpha$-MyHC allele and to the 5.1-kb fragment derived from the targeted allele. The 5.1-kb fragment is generated as a consequence of a StuI restriction site introduced by the neo portion of the $p g k \bullet n e o \bullet$ polyA cassette. This cassette consists of a neomycin selectable marker flanked by the phosphoglycerate kinase I gene promoter, and an SV40 poly $\mathrm{A}^{+}$addition signal.

Selection of targeted cell lines and generation of animals. $\quad$ E14.1 ES cells $(10,11)$ were cultured using mitomycin-treated mouse embryonic fibroblasts as feeder cells. All culture conditions and passages were as previously described (12). The targeting vector was linearized with NotI, and ES cells were electroporated using an Electro Cell Manipulator 600 Electroporation System (Biotechnologies and Experimental Research, Inc., San Diego, CA), plated and selected for resistance to G418 (GIBCO, Grand Island, NY) at a concentration of $200 \mu \mathrm{g} / \mathrm{ml}$. Gancyclovir (Sigma, St. Louis, MO) was added to $2 \mu \mathrm{M}$ on day 6 , and colonies resistant to both drugs were picked for subculture between days 10 and 12 . Subcultures were split $3 \mathrm{~d}$ later, one set used for preparation of DNA, and the other frozen for storage (13). DNA isolated from subcultures was subjected to Southern blot analysis as described above. Correctly targeted ES lines were obtained with an overall frequency of $14 \%$, the negative selection providing approximately a fivefold enrichment. Five targeted E14.1 ES cell lines were injected into blastocysts, and implanted into Swiss black recipient females. Of the 26 chimeric animals obtained, one transmitted the targeted mutation through the germ line.

Quantitative RNA analyses. Total RNA was isolated from the ventricular apexes of mice to be analyzed using TriReagent ${ }^{\circledR}$ (Molecular Research Center, Inc., Cincinnati, $\mathrm{OH}$ ) and a Tissuemizer homogenizer (Tekmar Co., Cincinnati, $\mathrm{OH}$ ) according to the manufacturer's protocol. The RNA was resuspended in water, quantitated by optical density at $260 \mathrm{~nm}$, diluted, denatured, and $2 \mu \mathrm{g}$ blotted to nitrocellulose filters using a dot-blot filtration manifold (Bio-Rad, Melville, NY). After blotting, the filters were baked at $80^{\circ} \mathrm{C}$ for $2 \mathrm{~h}$, prehybridized, hybridized and washed as described previously (14). Hybridization signals were quantitated using a PhosphorImager and ImageQuant software (Molecular Dynamics, Sunnyvale, CA). The signal intensity of each dot was normalized to the glyceraldehyde 3-phosphate dehydrogenase (GAPDH) signal in order to account for loading error which was $<5 \%$. The mean relative steady state transcript levels were calculated for $\alpha-M y H C^{+/+}$and $\alpha-M y H C^{+/-}$mice and expressed as a percentage of the wild type $\left(\alpha-\mathrm{MyHC}^{+/+}\right)$levels \pm 1 SEM. The oligonucleotide probes used for quantitation of the $\alpha-\mathrm{MyHC}$ and $\beta$-MyHC transcripts have been previously described $(15,16)$. The oligonucleotides used as transcript specific probes were as follows: atrial natriuretic factor (ANF); 5'-AATGTGACCAAGCTGCGTGACACACCACAAGGGCTTAGGATCTTTTGCGATCTGCTCAAG, $\alpha$-cardiac actin; 5'-CGTACAATGACTGATGAGAGATGGGGAGGGGGCTCAGAGGATTCCAAGAAGCACAATAC, $\alpha$-skeletal actin; 5'-TGGAGCAAAACAGAATGGCTGGCTTTAATGCTTCAAGTTTTCCATTTCCTTTCCACAGGG, brain natriuretic factor (BNP); CAGCTTGAGATATGTGTCACCTTGGAATTTTGAGGTCTCTGCTGGACCCGGAGGGTGCTG, myosin light chain 2 ventricular isoform (MLC2v); 5'-CACAGCCCTGGGATGGAGAGTGGGCTGTGGGTCACCTGAGGCTGTGGTT CAG, myosin light chain 2 atrial isoform (MLC2a); 5'-GAGGTGACCTCAGCCTGTCTACTCCTCTTTCTCATCCCCG, phospholamban (PLB); 5' -TGACGTGCTTGCTGAGGCATTTCAATAGTGGAGGCTCTCCTGATAGCCGAGCGAGTGAGG, essential myosin light chain 1 ventricular isoform (ELC1v); 5'-GGCTCAGCTCGCCATGATATGCTTCACAAACGCTTCTAGTTGATGCAC, essential myosin light chain 1 atrial isoform (ELC1a); 5'-CACCCTGGAGAAACGTGCTTTACCCAGACATGATGTGCTTGAC, angiotensin converting enzyme (ACE); 5'-CATGTTCACAGAGGTACACTGCTTGATCCTGAAGTCCTTGCC GTTGTAGAAGTCCCAGGC, titin; 5'-GTTTATCTA-GAGTTATGATTTCAATAGCTGGTGTTTTCTGACCCACCAC, and GAPDH; 5'-GgAACATGTAGACCATGTAGTTGAGgtCAATGAAG. All 
steady state transcript levels were normalized with respect to GAPDH signal intensity after correcting for background. Levels in the heterozygotes were expressed as a percentage of the particular transcript's level in the wild type ventricle \pm SEM. An unpaired, two-tailed Student's $t$-test was performed to determine whether the data were significantly different between groups of mice; significance being defined as $P \leq 0.05$. The relative steady state transcript levels calculated for the $\alpha-M y H C^{+/-}$animals fell into two categories which were significantly different as determined by the unpaired $t$-test.

Protein extractions and PAGE analyses. Protein was isolated using TriReagent according to the manufacturer's protocol. Total protein was extracted from the phenol phase and interphase of the RNA extractions described above after removal of DNA by ethanol precipitation and quantitated by Bio-Rad protein assay (Bio-Rad). For Western analyses, proteins were electrophoresed in $7 \%$ polyacrylamide gels containing $10 \%$ glycerol and $0.2 \%$ SDS such that the $\alpha$-MyHC and $\beta$-MyHC isoforms are resolved from one another. Proteins were transferred to nitrocellulose in $25 \mathrm{mMTris} \bullet \mathrm{HCl}, 192 \mathrm{mM}$ glycine, $5 \%$ methanol, at $150 \mathrm{~mA}$ for $12-18 \mathrm{~h}$. The filters were subjected to Western analysis using previously characterized antibodies. The BA-G5 (mouse monoclonal BA-G5; ATCC, Rockville, MD) antibody is specific for the $\alpha$-MyHC isoform (17), while the other, (mouse monoclonal 3-48; Accurate Chemical \& Scientific Corporation, Westbury, $\mathrm{NY}$ ), is pan specific for striated MyHCs. The epitopes for these antibodies differ from one another but are not defined. Detection was with a BioMax chemiluminescent detection kit and BioMax MR or BioMax Light film (Kodak, Rochester, NY). Blots were stripped by two 10-min incubations in $6 \mathrm{M}$ guanidine followed by two washes in water, and two in TBS, and then were re-probed as indicated.

For determination of relative MyHC levels, protein extracts were electrophoresed in $10 \%$ polyacrylamide gels containing $0.2 \%$ SDS (see Fig. $3 \mathrm{~B}$ ). The gels were electrophoresed for $5-6 \mathrm{~h}$ at $35 \mathrm{~mA}$, fixed in $30 \%$ methanol, $10 \%$ acetic acid for $20 \mathrm{~min}$, and stained using Brilliant Blue G-Colloidal protein stain (Sigma) according to the manufacturer's instructions. Bands corresponding to the $\alpha$-MyHC protein were quantitated (NIH Image software), the values normalized with respect to a previously identified non-myofibrillar protein band (Gulick, J., and J. Robbins, unpublished results) or actin, and expressed as a percentage of wild type (see Fig. $3 \mathrm{C}$ ). The relative protein levels were compared using an unpaired two-tailed Student's $t$-test, and $P \leq 0.05$ was used to determine significance. Protein data points were judged as outlyers if they fell farther than one standard deviation from the mean and were excluded from the subsequent analyses. The data are expressed as means for each genotype \pm SEM.

Isolated perfused working heart preparation. The working heart preparations were essentially as described previously $(2,18,19)$. The animals were age-matched males (12-25 wks post-birth) from the same litters. Briefly, a 20 gauge cannula was tied into the aortic stump to allow regulation and recording of MAP (Starling Resistance) and aortic flow (Transonic flow probe model T206; Transonic Systems, Inc., Ithaca, NY). Another 20 gauge cannula was tied into one left pulmonary vein to accommodate regulation and recording (Transonic flow probe model T206; Transonic Systems, Inc.) of venous return and left atrial pressure: venous return = cardiac output; venous return minus aortic flow $=$ coronary flow. Left intraventricular pressure (IVP) was measured as systolic, diastolic and end diastolic pressure (see Fig. $4 A$ ). The recording, amplification and differentiation system was from Grass Instruments (models 7DA, 7PHA, 7P1, 720; Quincy, MA). The fluid filled catheter system responded well within experimental requirements, without distortion up to a frequency of 600-bpm. Custom designed software calculated heart rate (HR, calculated from an EKG R-R interval), MAP, IVP, peak systolic pressure, time to peak pressure (TPP), half time of relaxation $\left(\mathrm{RT}_{1 / 2}\right)$, the first derivatives of the change in left ventricular systolic pressure with respect to time $( \pm d P / d t)$, aortic and coronary flow, venous return (cardiac output), left ventricular minute work $(\mathrm{MAP} \times \mathrm{CO})$, stroke volume $(\mathrm{SV}=\mathrm{CO} / \mathrm{HR})$, stroke work $(\mathrm{SV} \times \mathrm{MAP})$, left atrial pressure, and perfusate temperature. The arterial $\mathrm{P}_{\mathrm{O} 2}$ was $650 \mathrm{mmHg}$, and the
$\mathrm{P}_{\mathrm{CO} 2} \sim 30 \mathrm{mmHg}$. The data from the working heart preparations were expressed as mean \pm SEM. Starling curves were generated by linear regression using Statview, version 4.01 (Abacus Concepts Inc., Berkeley, CA). For regression lines, the slopes and $r$ values are shown (see legend, Fig. $4 B$ ). The regression lines were compared using an $\mathrm{F}$ test; the equation used to calculate the $\mathrm{F}$ statistic was [ $\mathrm{SSE}_{1,2^{-}}$ $\left.\left(\mathrm{SSE}_{1}+\mathrm{SSE}_{2}\right) \div 2\right] \div\left[\left(\mathrm{SSE}_{1}+\mathrm{SSE}_{2}\right) \div\left(\mathrm{n}_{1}+\mathrm{n}_{2}-4\right)\right]$ with 2 and $\left(\mathrm{n}_{1}+\right.$ $\left.n_{2}-4\right)$ degrees of freedom, where SSE is the residual sum of squares $(20,21)$.

Histologic analyses. Mice were anesthetized, the hearts removed while still beating, drained of blood, weighed, measured from the base to apex, and fixed by perfusion (using PBS containing $2 \%$ paraformaldehyde and $1 \%$ glutaraldehyde) through the apex with a 20 gauge needle. The hearts were dehydrated through a graded series of alcohols and paraffin embedded with apex down; care was taken to orient all of the hearts similarly. Step serial sections $(5 \mu \mathrm{m})$ were taken every $75 \mu \mathrm{m}$ from apex to base and mounted on slides. Adjacent sections were stained with hematoxylin and eosin or with trichrome and examined microscopically. The entire procedure, including pathological examination, was done blind with respect to the genotype of the hearts ( $4 \alpha-M y H C^{+/+}$and $\left.8 \alpha-M y H C^{+/-}\right)$. Photomicrographs were taken with an Olympus Vanox photomicroscope.

Transmission electron microscopy. Mice were anesthetized, the hearts removed while still beating, and immersed in a cardioplegic solution ( $25 \mathrm{mM} \mathrm{KCl}, 5 \%$ dextrose in PBS) to ensure complete myocardial relaxation. The left atrial flaps were removed, and an incision made from this hole to the apex of the heart. Samples of ventricular tissue were removed for RNA isolation as described above. The heart was fixed as above and $1 \mathrm{~mm}^{2}$ blocks were dissected from the following locations for embedding and sectioning; the left atrial appendage; left ventricular free wall, along the incision mentioned above at the largest diameter of the ventricle (two blocks); along the same incision toward the apex of the ventricle. The blocks were trimmed, embedded in epon, stained with methylene blue and thick sections collected. These sections were viewed to determine the orientation of the myofibers and blocks were re-oriented to obtain transverse sections. Thin sections were cut, picked up on uncoated 300 mesh grids and viewed using a Zeiss 912 transmission electron microscope. Grids were scanned at low magnification $(80 \times)$, and areas containing transversely sectioned cardiomyocytes identified. These were viewed and photographed at $\times 500-20,000$. Multiple $(>100)$ fields from various regions of two individual hearts of each genotype were examined; the photographs shown are representative of these.

\section{Results}

Production of animals and transmission of the targeted allele. ES cells containing a targeted disruption of $\alpha$ - $M y H C$ were obtained by homologous recombination and used to colonize the germ line of mice (Fig. $1 A$ ). Breeding of animals heterozygous $(+/-)$ for the disrupted locus produced only $\alpha-M y H C^{+/-}$and $\alpha$-MyHC$C^{+/+}$offspring (Fig. $1 B$ ); no $\alpha-M y H C^{-/-}$mice survived to term demonstrating the lethality of the $\alpha-M y H C^{-1-}$ genotype. A genotypic ratio of $74+/+; 132+/-; 0-/-$ from the $F_{1}$ generation was observed approximating the 1:2:0 ratio characteristic of recessive lethal transmission. Timed pregnancies were used to confirm that the disrupted $\alpha-M y H C$ allele is homozygous lethal with embryonic death occurring 11-12.5 d post coitum. Animals heterozygous for the null allele $\left(\alpha-M y H C^{+-}\right)$ were viable and overtly normal. Both sexes were fertile and generated normal litter sizes when outbred to wild type mice.

Gene expression in $\alpha-M y H C^{+/-}$animals. RNA dot blot analyses were used to determine the relative $\alpha-M y H C$ and $\beta$ - $M y H C$ transcript levels in ventricular RNAs isolated from the $\alpha-M y H C^{+-}$and wild type animals (Fig. 2). The $\alpha-M y H C$ 
A

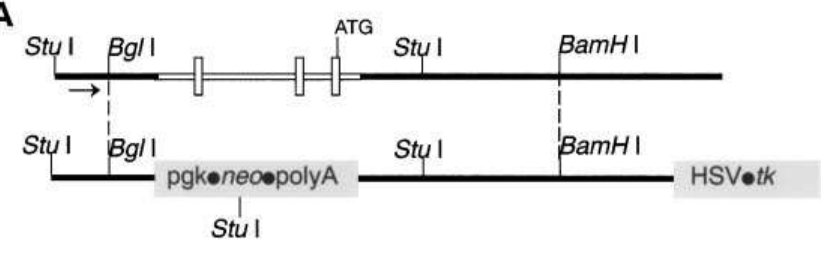

B

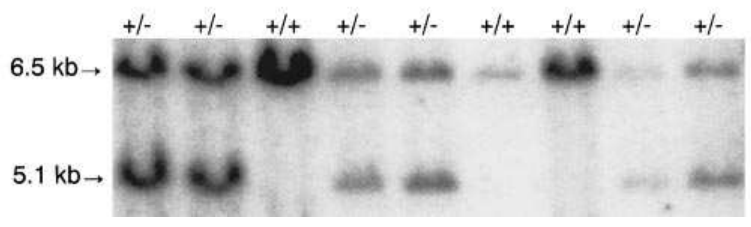

Figure 1. Targeting strategy and Southern blot analyses. $(A)$ The top line is a schematic diagram of the $\alpha-M y H C$ gene. The region replaced in the construction of the targeting vector is indicated (open line), and includes the first 3 exons of the $\alpha-M y H C$ transcript (open boxes) which encode the $5^{\prime}$ untranslated region and the initiating methionine codon. The bottom line is a map of the targeting construct used for electroporation; the dotted lines indicate the limits of the region in which homologous recombination occurred. The deleted portion of the $\alpha-M y H C$ gene was replaced with a neomycin resistance cassette ( $p g k \bullet$ neo $\bullet$ polyA) for positive selection of the targeted ES cells. A Herpes Simplex Virus thymidine kinase $(\mathrm{HSV} \bullet t k)$ selectable marker at the $3^{\prime}$ end allowed negative selection against the ES cell lines with non-homologous integration events. Correctly targeted cell lines and animals bearing the targeted allele were detected by Southern blot analysis using a DNA probe $(\rightarrow)$ located external to the targeting construct (see Methods). This probe detects a novel StuI restriction fragment, the result of a StuI site in neo, and is diagnostic for the targeting event. (B) Southern blot analyses of DNA derived from a litter of an $\alpha-M y H C^{+/-} \times \alpha-M y H C^{+1-}$ cross. Targeted ES cell lines were used to generate chimeric mice (see Methods) which were outbred to verify germ line transmission of the targeted $\alpha$ - $M y H C$ allele. Genomic DNA's were isolated from tail clips of $F_{i}$ 's derived from an $\alpha-\mathrm{MyHC}^{+/-} \times \alpha-M y H \mathrm{C}^{+/-}$cross, and a Southern blot carried out on the StuI-digested material. The radiolabeled probe $(\rightarrow)$, detects the normal $6.5-\mathrm{kb}$ StuI fragment, as well as the novel $5.1-\mathrm{kb}$ fragment in $\alpha-\mathrm{MyHC}^{+/-}$heterozygotes $(+/-)$. Only the normal 6.5 -kb fragment is detected in the wild type $(+/+)$ mice. Heterozygous matings produced only $\alpha-M y H C^{+/-}$and $\alpha-M y H C^{+/+}$offspring.

transcript steady state levels in the $\alpha-M y H C^{+/-}$animals are reduced to approximately half those observed in the $\alpha-\mathrm{MyHC}^{+/+}$ mice $\left(56.1 \pm 2.0 \%\right.$ for $\alpha-M y H C^{+/-}$versus $100 \pm 3.6 \%$ for $\left.\alpha-M y H C^{+/+} ; P \leq 0.0001\right)$. There is a small but significant increase in the steady state level of the $\beta-M y H C$ transcript among the heterozygotes. Nevertheless, the $\beta-M y H C$ transcript levels are never more than $7 \%$ of the $\alpha-M y H C$ levels, and we never observed a major up-regulation of $\beta$-MyHC transcription in response to the dramatically lowered $\alpha-M y H C$ transcript levels. This contrasts with a 30-50-fold induction of $\beta$ - $M y H C$ observed in hypothyroid mice, which illustrates the

Figure 2. Analyses of cardiac specific gene expression in $\alpha-M y H C^{+/-}$ and $\alpha-\mathrm{MyHC}^{+/+}$mice. Duplicate blots were made using RNA isolated from ventricles of $\alpha-M y H C^{+/-}$(underlined numbers) and $\alpha-M y \mathrm{HC}^{+/+}$mice aged from 11-15-wk post-birth. Oligonucleotide

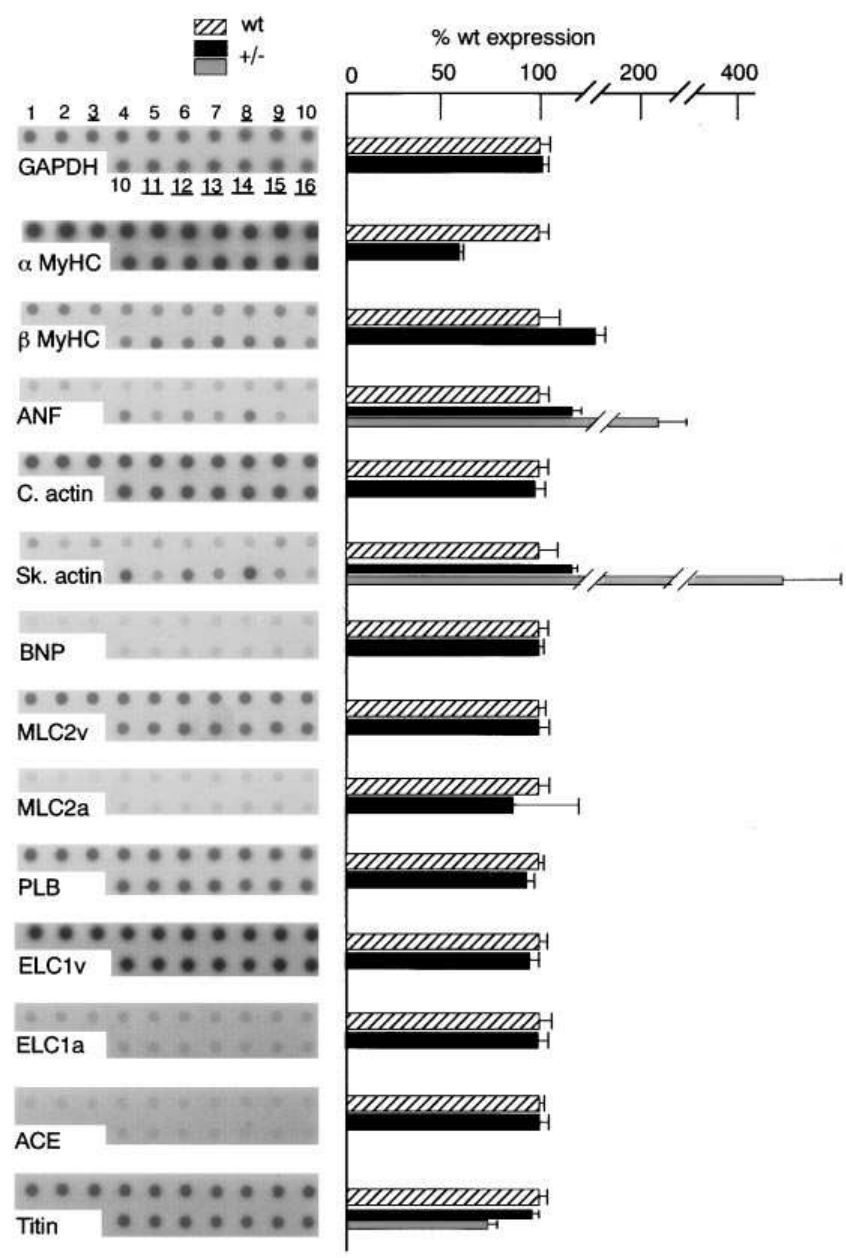

probes specific for the transcripts indicated were used and hybridization quantitated using a PhosphorImager (see Methods). All hybridization signals were normalized with respect to GAPDH and expressed as a percentage of the particular transcript's expression level in control ventricles. Error bars shown indicate standard errors of the mean. The $\alpha-M y H C$ transcript levels are reduced from $100 \pm 3.6 \%$ $\left(\alpha-M y H C^{+/+}\right)$to $56.1 \pm 2.0 \%$ for $\alpha-M y H C^{+/-}(P \leq 0.0001)$. Although the absolute amount of $\beta-M y H C$ transcript remains a small percentage of the total MyHC transcript in the ventricle, there is a significant increase, relative to the very low levels normally found in the euthyroid ventricle $(141.7 \pm 9.8 \%, P \leq 0.0001)$. There is a significant increase in the steady state level of the ANF transcript (165 $\pm 18.8 \%$; $P \leq 0.05)$ and a noticeable though statistically insignificant increase in the skeletal $\alpha$-actin transcript level $(236 \pm 61.5 \% ; P=0.054)$. The transcript levels for ANF and skeletal $\alpha$-actin are separable into two statistically different groups. One group $(n=6)$ showed ANF transcript levels that are $134 \pm 4.0 \%$ and skeletal $\alpha$-actin levels that are $129 \pm 13.5 \%$ ( $P \leq 0.001$ and 0.079 respectively). The second group $(n=3)$, showed ANF transcript levels of $229 \pm 35.4 \%$ and skeletal $\alpha$-actin levels that are $452 \pm 91.5 \%$ relative to $100 \% \pm 4.7 \%$ and $100 \% \pm 8.5 \%$ for controls $(P \leq 0.0001$ and 0.0001 respectively; in both cases; indicated by the broken bars on the histogram bars). The steady state level of the titin transcript was significantly reduced in the same group of three $(73.5 \pm 5.15$ versus $100 \pm 5.0 \% ; P=0.016)$ but not in the group of $6(94 \pm 4.9 \% ; P=0.4)$. There were no statistically significant differences between levels for the other transcripts. The levels for these transcripts in the heterozygotes relative to the wild type were: cardiac actin, $95.3 \pm 3.9 \%(P=0.419)$; BNP, $101.2 \pm 4.8 \%$ $(P=0.863)$; MLC2v, $97.2 \pm 5.7 \%(P=0.664) ; \mathrm{PLB}, 91.6 \pm 4.3 \%(P=$ $0.307)$; MLC1a, $100 \pm 16.2 \%(P=0.989) ;$ MLC1v, $82 \pm 5.5 \%(P=$ $0.094)$; and MLC2a, $82.8 \pm 31.7 \%(P=0.051)$. 
A

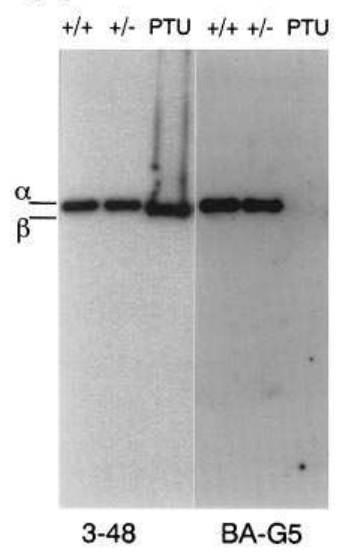

B

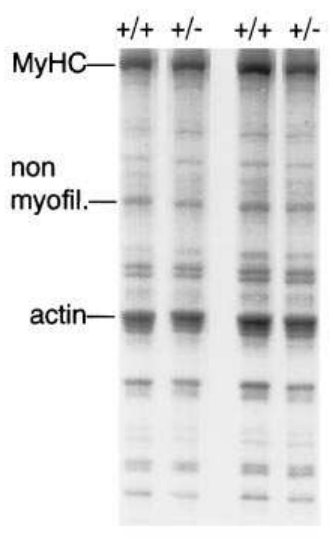

C

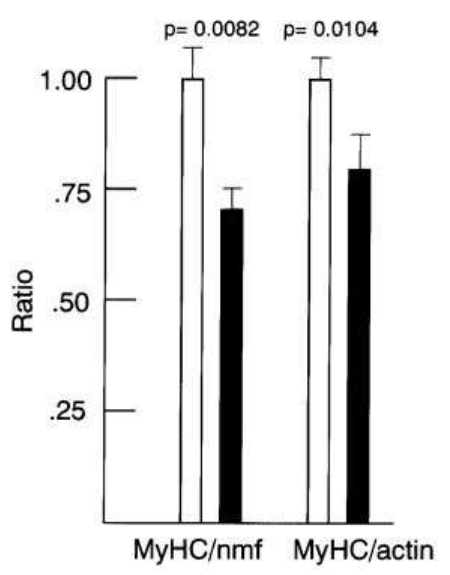

Figure 3. Qualitative and quantitative analysis of $\mathrm{MyHC}$ protein in $\alpha-\mathrm{MyHC}^{+/-}$and $\alpha-M y H C^{+/+}$mouse ventricles. (A) Western blot containing ventricular protein extracts from two representative $\alpha-M y H C^{+/+}$ $(+/+) \alpha-M_{y H C} C^{+/-}(+/-)$ventricles and a hypothyroid ventricular apex (PTU). The blots represent chemiluminescent exposures after hybridization with the BA-G5 ( $\alpha$-MyHC-specific) antibody and from the re-probing with the 3-48 (pan-specific) antibody. The specificity of the BA-G5 antibody is confirmed by the lack of a signal in the PTU-treated ventricle. The 3-48

antibody detects the $\beta$-MyHC in the hypothyroid sample (PTU) as well as the $\alpha$-MyHC. Note that the MyHC isoforms exhibit differential mobility under these conditions and no significant amount of $\beta$-MyHC is detected in either the $\alpha-M y H C^{+/+}$or $\alpha-M y H C^{+/-}$ventricle under euthyroid conditions. Even upon long exposure extraordinary bands are not detected by either antibody in samples from the $\alpha-M y H C^{+/-}$ventricles $($Jones, W.K., and J. Robbins, unpublished results). (B) Protein extracts from 2 representative $\alpha-M y H C^{+/-}(+/-)$and $\alpha-M y H C^{+/+}(+/+)$sets of ventricles. Each lane contains approximately $2 \mu \mathrm{g}$ of total protein, and the band intensities were determined after digitizing the stained gels (see Methods). (C) Graphic representation of MyHC levels normalized to the levels of a non-myofilament protein (nmf) and to actin. In $\alpha-M y H C^{+/-}$ventricles, the MyHC level relative to nmf was $73.5 \% \pm 4.2 \%(n=7)$ relative to $100 \pm 7.3 \%(n=6)$ for $\alpha-M y H C^{+/+}$animals $(P=0.0082)$. The MyHC:actin ratio was reduced in the heterozygotes $(78.4 \pm 13.6 \%)$ relative to the wild type $(100 \pm 11.9 \% ; P=0.0104)$.

magnitude of change needed to effect an isoform shift in the heart (2). Thus, ablation of $\alpha-M y H C$ results in a gene dosage effect upon the level of the $\alpha-M y H C$ transcript and $\beta$ - $M y H C$ upregulation does not compensate for the deficit. The term, gene dosage effect, is used in the classical genetic sense; reduction of gene copy by null mutation results in a decrease in the primary gene product. Normal induction of $\beta-M y H C$ and repression of $\alpha-M y H C$ in $\alpha-M y H C^{+/-}$animals made hypothyroid via propylthiouracil treatment was observed (Jones, W.K., and J. Robbins, unpublished results). These data indicate that the regulation of $\beta-M y H C$ and $\alpha-M y H C$ are not grossly changed in the $\alpha-M y H C^{+-}$mice and imply that no gross rearrangement of the $\beta-M y H C \rightarrow \alpha-M y H C$ region occurred.

The effect of heterozygosity for the $\alpha-M y H C$ null allele upon transcription of specific genes that are (or can be) expressed in the ventricle was studied by RNA dot blot analyses using ventricular RNAs from the same age-matched group of $\alpha-M y H C^{+/-}$and $\alpha-M y H C^{+/+}$animals. No significant changes in the levels of GAPDH, cardiac actin, BNP, MLC2v, MLC1a, ACE, and PLB were detected. As noted, there was a slight but significant increase in the steady state level of the $\beta$-MyHC transcript. We also noted significant increases in the levels of the ANF and skeletal $\alpha$-actin transcripts. Interestingly, the heterozygous $\alpha-\mathrm{MyHC}^{+/-}$mice fall into two categories. One group, consisting of six animals, shows a significant increase in ANF transcript levels $(133 \pm 4.0 \% ; P \leq 0.0001)$ and a small but statistically insignificant increase in the skeletal $\alpha$-actin transcript levels $(129 \pm 13.5 \% ; P=0.079)$ relative to the $\alpha-M y H C^{+/+}$animals. The second group, consisting of three animals, shows a significant increase in the steady state levels for both ANF and skeletal $\alpha$-actin $(229 \pm 35 \% ; P \leq 0.0001$, and $452 \pm 91.5 \% ; P \leq$ $0.0001)$. The steady state levels of these transcripts are significantly different between the two groups of $\alpha-\mathrm{MyHC}^{+/-}$animals ( $P \leq 0.005$ for ANF and $P \leq 0.001$ for skeletal actin). The same two groups of $\alpha-M y H C^{+/-}$animals have significantly dif- ferent levels of titin transcripts $(P=0.038)$. The first group $(n=6)$ had steady state levels of titin transcript that were $94 \pm 4.9 \%$ relative to $100 \pm 5.0 \%(P=0.40)$ for $\alpha-M y H C^{+/+}$ ventricular RNA. The second group $(n=3)$ had a significant reduction of the titin transcript level to $73.5 \pm 5.1 \%(P=0.016)$ of the wild type level. We observed no significant alterations of the other transcript levels tested between these two groups of heterozygotes.

To determine whether there was an accumulation of $\beta$-MyHC or the presence of truncated $\alpha-M y H C$ peptides expressed from the targeted $\alpha-M y H C$ allele, protein extracts from $\alpha-M y H C^{+/-}$and $\alpha-M y H C^{+/+}$ventricles were electrophoresed under conditions which allow resolution of the $\mathrm{MyHC}$ isoforms and blotted to nitrocellulose. The blot was probed with the BA-G5 antibody ( $\alpha-M y H C$ specific), developed, and then stripped and re-probed with the 3-48 antibody which detects all striated MyHC isoforms (see Methods). The BA-G5 antibody detected the $\alpha-M y H C$ protein equally well in both $\alpha-M y H C^{+/+}$and $\alpha-M y H C^{+/-}$extracts and did not detect $\mathrm{MyHC}$ protein in the ventricular extract from hypothyroid wild type mice, where $\beta$-MyHC is the predominant isoform (Fig. 3 A). The 3-48 antibody detected both MyHC isoforms equally well. As distinguished by mobility, there was no significant accumulation of $\beta$-MyHC or the other striated $\mathrm{MyHC}$ isoforms in the heterozygote ventricles (Fig. $3 A$ ). Furthermore, novel MyHC protein species were not detected in the $\alpha-M y H C^{+/-}$protein extracts by either antibody, evidence that a truncated polypeptide (detectable by these antibodies) was not made from the targeted $\alpha-M y H C$ allele.

We wished to determine whether the decrease at the transcript level was reflected by changes in the steady state protein pool. For a null mutation of a structural gene to have phenotypic consequences, the level of the cognate protein is usually reduced, and the deficit is not compensated for by the synthesis of a functionally equivalent isoform. To address this issue, 


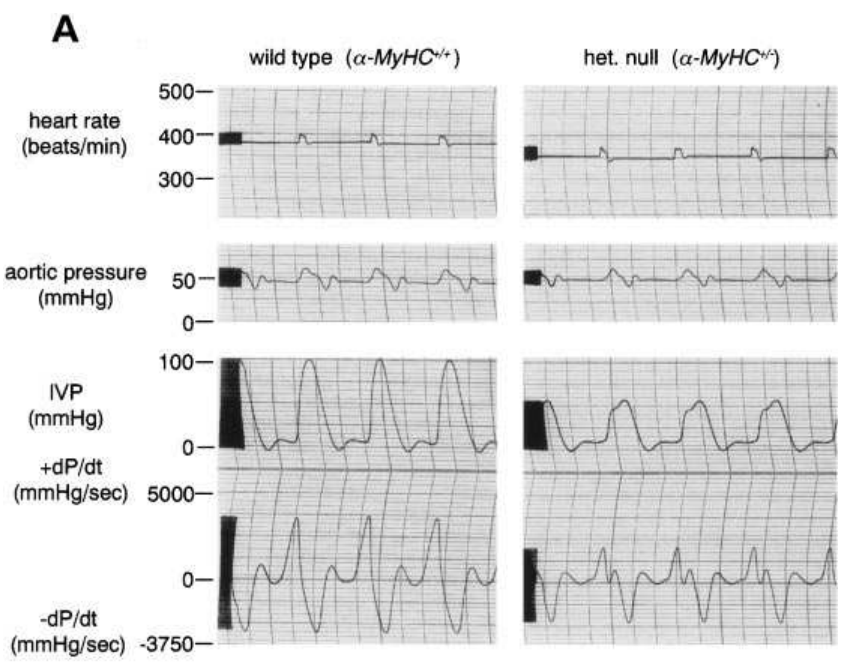

B

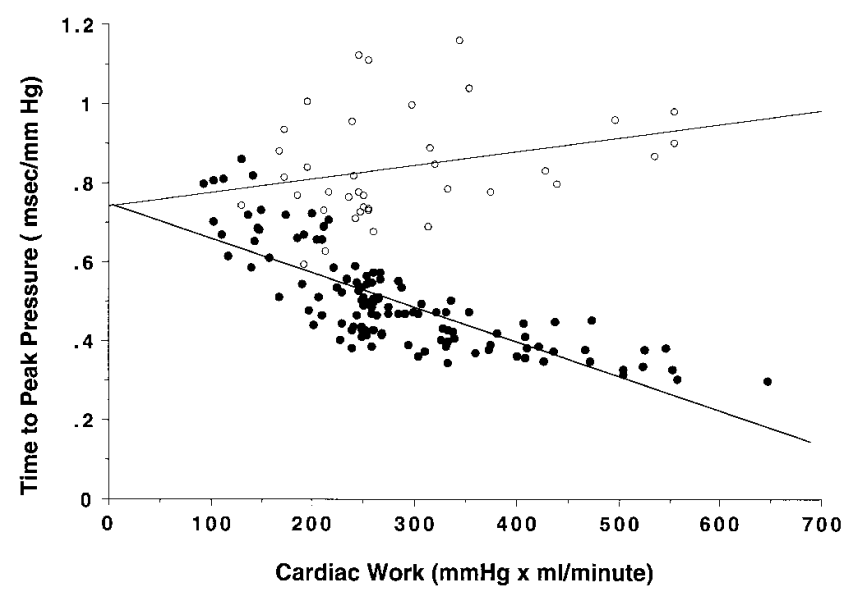

Figure 4. Physiological analyses of left ventricular function. $(A)$ Chart recordings from work performing heart preparations from $\alpha-M y H C^{+/+}$and $\alpha-M y H C^{+/-}$mice (see Methods). The experimental animals were males aged 12-25-wk post-birth. The baseline recordings were taken under similar load conditions: MAP (afterload), $\sim 50$ $\mathrm{mmHg}$; venous return, $\sim 5 \mathrm{ml} / \mathrm{min}$; $\mathrm{LV}$ minute work, $\sim 250 \mathrm{mmHg} \times$ $\mathrm{ml} / \mathrm{min}$; heart rate, 360-390-bpm. The resulting left IVP and the rate of pressure development $(+d P / d t$ and $-d P / d t)$ are shown. The $+\mathrm{dP} /$ $\mathrm{dt}$ and $-d P / d t$ values reflecting the contractility and relaxation of the heart were; +3600 and -3050 for the $\alpha-M y H C^{+/+}$animals; and +2000 and $-2225 \mathrm{mmHg} / \mathrm{msec}$ for the $\alpha-M y H C^{+/-}$mice, respectively. (B) TPP plotted against left ventricular minute work. The data were obtained by varying preload and afterload to cover the range of left ventricular minute work from $100-600 \mathrm{mmHg} \times \mathrm{ml} / \mathrm{min}$. As expected from the Frank-Starling relationship, the $\alpha-M y H C^{+/+}$hearts (closed circles, 122 measurements from eight hearts; $r=0.771$ ) show a strong negative correlation of TPP to increased left ventricular work. The data for the $\alpha-M y H C^{+/-}$hearts that demonstrated compromised Starling function includes 38 data points from 3 hearts (open circles), and showed no correlation between load and contractility $(r=0.280)$. The slopes of the two regression curves were $-8.1 \times 10^{-4}$ $\left(\alpha-\mathrm{MyHC}^{+/+}\right)$and $3.5 \times 10^{-4}\left(\alpha-\mathrm{MyHC}^{+/-}\right)$and are significantly different $(P \leq 0.001)$. the MyHC content of the $\alpha-M y H C^{+/-}$and $\alpha-M y H C^{+/+}$ventricles were compared. Total protein extracts were prepared from $\alpha-M y H C^{+/-}$and $\alpha-M y H C^{+/+}$animals, and subjected to SDS-glycerol PAGE. Quantitative analysis of stained gels (see Methods) indicated an overall reduction of MyHC protein in $\alpha-M y H C^{+l-}$ ventricles relative to the wild type. For these analyses, the intensity of the $\mathrm{MyHC}$ bands were normalized relative to the intensity of a non-myofilament protein species within the same lane of the gel (Fig. $3 \mathrm{~B}$ ). This non-myofibrillar band was identified by comparison of banding patterns in whole myocardial protein extracts to extracts adapted for the isolation of myofibrillar proteins (Gulick, J., and J. Robbins, unpublished results). A reduction to $73.5 \pm 4.2 \%$ relative to $100 \pm 7.3 \%$ for the $\alpha-M y H C^{+/+}$protein was observed. This reduction was significant at the $P=0.0082$ level (two tailed $t$-test). The intensities of the bands corresponding to the actin protein were similarly quantitated, and the MyHC:actin ratios calculated. A reduction in the ratio to $78.4 \pm 13.6 \%$ relative to the wild type $(100 \pm 11.9 \%)$ was noted which was significant at the $P=0.0104$ level. There was no significant correlation between $\alpha$-MyHC protein and the transcript levels among the $\alpha-\mathrm{MyHC}^{+/-}$ventricles $(\mathrm{r}=0.3284)$. That the measured reduction in $\mathrm{MyHC}$ protein is less than the reduction in transcript level may reflect the effects of MyHC protein stability and/or modifier loci.

Functional analysis of $\alpha$-MyHC ${ }^{+/-}$hearts. To investigate the effect(s) of MyHC deficiency upon cardiac function, a group of age and sex matched (males 12-25 wk post-birth) $\alpha-M y H C^{+/-}$and $\alpha-M y H C^{+/+}$animals were subjected to physiological analyses using the isolated working heart preparation ( $2,18,19$, see Methods). Representative tracings showing the functional phenotype are displayed (Fig. $4 A$ ). These tracings show data collected under identical baseline load conditions during the perfusion of a wild type and an $\alpha-M y H C^{+/-}$heart. The baseline conditions used were: mean aortic pressure 50 $\mathrm{mmHg}$, cardiac output $5 \mathrm{ml} / \mathrm{min}$, heart rate 360-390-bpm and cardiac minute work, $250 \mathrm{mmHg} \times \mathrm{ml} / \mathrm{min}$ (18). In spite of an identical load, the $\alpha-M y H C^{+/-}$hearts produced systolic intra-

Table I. Means \pm SEM of Measured Cardiac Parameters ( $\mathrm{mmHg}$ )

\begin{tabular}{lcc}
\hline & $\begin{array}{c}\text { Control } \\
(n=8)\end{array}$ & $\begin{array}{c}\text { Heterozygous } \\
(n=8)\end{array}$ \\
\hline Intraventricular pressure & & \\
$\quad$ Systolic & $99.7 \pm 2.1$ & $85.8 \pm 6.8$ \\
$\quad$ Diastolic & $-8.1 \pm 2.4$ & $1.0 \pm 2.5^{*}$ \\
End diastolic & $7.3 \pm 3.3$ & $14.7 \pm 4.8$ \\
Mean atrial pressure & $6.8 \pm 1.0$ & $4.8 \pm 0.7$ \\
Peak rate of pressure development & & \\
$\quad(\mathrm{ms} / \mathrm{mmHg})$ & & \\
$+d P / d t$ & $3937 \pm 125$ & $2638 \pm 236^{\S}$ \\
$-d P / d t$ & $3589 \pm 269$ & $2244 \pm 162^{\S}$ \\
Duration of pressure change & & \\
$\quad(\mathrm{ms} / \mathrm{mmHg})$ & & \\
TPP & $0.43 \pm 0.02$ & $0.70 \pm 0.09^{\ddagger}$ \\
$\mathrm{RT}$ & & \\
& & \\
\hline
\end{tabular}

$* P<0.05,{ }^{\ddagger} P<0.01,{ }^{\S} P<0.001$, heterozygote vs. control, unpaired Student's $t$-test. 

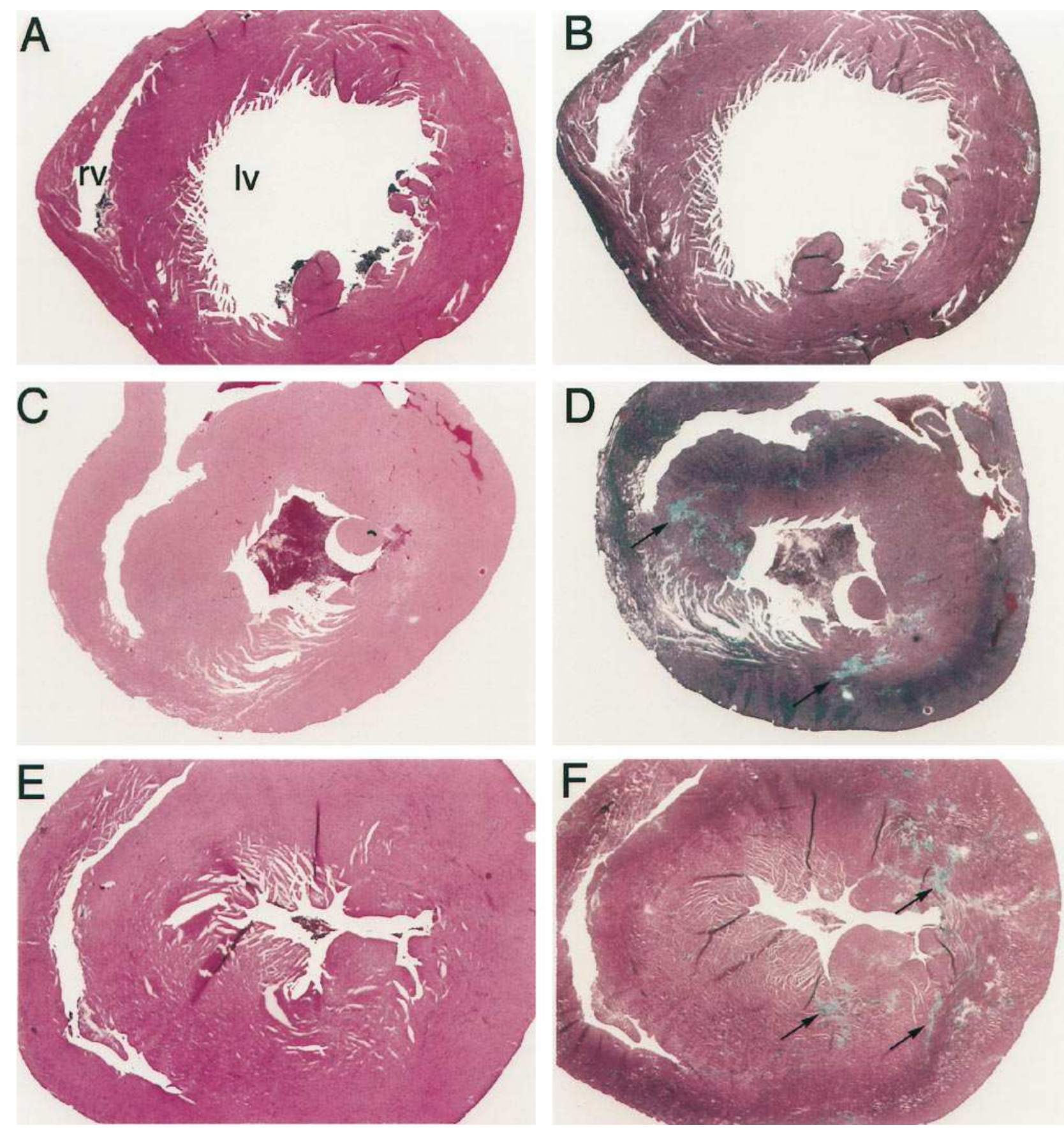

Figure 5. Histopathology of mouse hearts. Hearts were removed from four wild type and eight $\alpha-M y H C^{+/-}$animals fixed and mounted in paraffin blocks apex down. Adjacent step serial sections $(5 \mu \mathrm{m})$ were taken every $75 \mu \mathrm{m}$ and were stained with hematoxylin and eosin or with trichrome (see Methods). The sections were subjected to analysis in a blind fashion with respect to genotype. Representative transverse sections of hearts from heterozygous $\alpha-M y H C^{+/-}$animals stained with hematoxylin and eosin $(C$ and $E)$ or trichrome $(D$ and $F)$ are shown. These sections were matched to the wild type sections shown in panels A and B with regard to the position within the heart. The focal fibrotic lesions shown are characteristic of lesions seen in 5/8 heterozygous hearts examined (arrows, $D$ and $F$ ). No such lesions were seen in the ventricles of wild type $\alpha-M y H C^{+/+}$animals $(B)$. (A) shows a wild type section stained with hematoxylin and eosin. Although the hearts were fixed under identical conditions and were not significantly different in overall weight or measure, several of the heterozygous hearts showed a definite thickening of the left ventricular wall and septum. In a few cases, this extended to the right ventricular wall (see Results). lv, left ventricle; rv, right ventricle. $\times 14$.

ventricular pressures (IVPs) which were $14 \mathrm{mmHg}$ lower than the wild type and diastolic IVPs $9 \mathrm{mmHg}$ higher than the corresponding wild type values (Table I). The maximal rates of pressure development were significantly reduced relative to the control hearts: $+d P / d t$ was reduced by $33 \%$ and $-d P / d t$ was reduced by $37 \%$.

Two other parameters of cardiac function, time to peak pressure (TPP) and the half-time of relaxation $\left(\mathrm{RT}_{1 / 2}\right)$, were 
derived from the IVP tracings (Fig. $4 A$ ) and compared. TPP is defined as the time between the beginning of systole and the peak development of pressure while $\mathrm{RT}_{1 / 2}$ is the time from the peak IVP to the point of $50 \%$ ventricular relaxation. Both parameters were normalized with respect to peak IVP, since they are dependent upon the extent of pressure development. The TPP of the $\alpha-M y H C^{+/-}$hearts was $63 \%$ longer than that of the wild type and the $\mathrm{RT}_{1 / 2}$ of the $\alpha-M y H C^{+-}$hearts was $44 \%$ longer than that of the wild type. The increased TPP indicates that the $\alpha-M y H C^{+/-}$hearts have significantly reduced contractility (longer time to develop peak ventricular pressure), while the increased $\mathrm{RT}_{1 / 2}$ shows that relaxation is also prolonged (Table I).

To determine to what extent the $\alpha-M y H C^{+/+}$and $\alpha-\mathrm{MyHC}^{+/-}$hearts could be loaded with increasing afterload (MAP) and/or volume (CO) (cardiac output) loads, cardiac minute work $(\mathrm{MAP} \times \mathrm{CO})$ was varied from $100-600 \mathrm{mmHg} \times$ $\mathrm{ml} / \mathrm{min}$, and the results plotted as Starling function curves (Fig. $4 \mathrm{~B}$ ). The wild-type hearts showed a strong negative correlation $(\mathrm{r}=0.77)$ of TPP to increased left ventricular minute work, exhibiting a classic Starling response (Fig. $4 \mathrm{~B}$, filled circles). Data collected from similar experiments with $\alpha-M y H C^{+/-}$ animals showed that as with the levels of cardiac specific transcripts, the heterozygous mice fell into two groups. When stressed in this manner, three of the eight heterozygotes tested demonstrated severely impaired cardiac function, and no discernible Starling curve. There was no relationship between TPP and cardiac work in these three hearts, indicating the lack of a Starling response (Fig. 4 B, open circles). The remaining five heterozygous hearts did demonstrate Starling function ( $\mathrm{r}=0.63$, Jones, W.K., and J. Robbins, unpublished results), despite altered baseline cardiac parameters. Similar results were obtained when $+d P / d t$ and $\mathrm{RT}_{1 / 2}$ were plotted against cardiac work (see Methods). Other than a significant decrease in $-d P / d t(1833 \pm 145$ for the group lacking Starling function versus $2490 \pm 164$ for the group of five heterozygous mice) there were no significant differences between functional parameters recorded for the two groups of $\alpha-M y H C^{+/-}$hearts.

Histologic analyses. A group of 12 age-matched male mice (four $\alpha-M y H C^{+/+}$and eight $\alpha-M y H C^{+/-}$) were examined to determine the histopathological consequences, if any, of heterozygosity for the $\alpha-M y H C$ null allele. The hearts were paraffin embedded, sectioned $(5 \mu \mathrm{m})$ transversely from the apex to the base, and sections were examined after hematoxylin and eosin or trichrome staining. All observations and techniques were carried out blind with respect to the genotypic identity of the hearts. The four wild type animals showed no remarkable lesions or abnormalities (Fig. 5, $A$ and $B$ ). However, several distinct pathologic changes in the $\alpha-M y H C^{+-}$hearts were noted. In 5/8 $\alpha-M y H C^{+/-}$hearts, there were multifocal areas of fibrosis (Fig. 5, $D$ and $F$ ). The most common locations were in the apex (3/5 hearts) and left ventricular free wall (5/5 hearts). Lesions were randomly located in the endocardium, myocardium, or perivascular regions. Fibrosis was also frequently present in the right ventricle and the interventricular septum (3/5 hearts). Although there was no overall disorganization/ disarray of myocytes, a mild myofiber disarray was seen adjacent to areas of fibrotic lesions (Fig. 6). Of the five hearts with
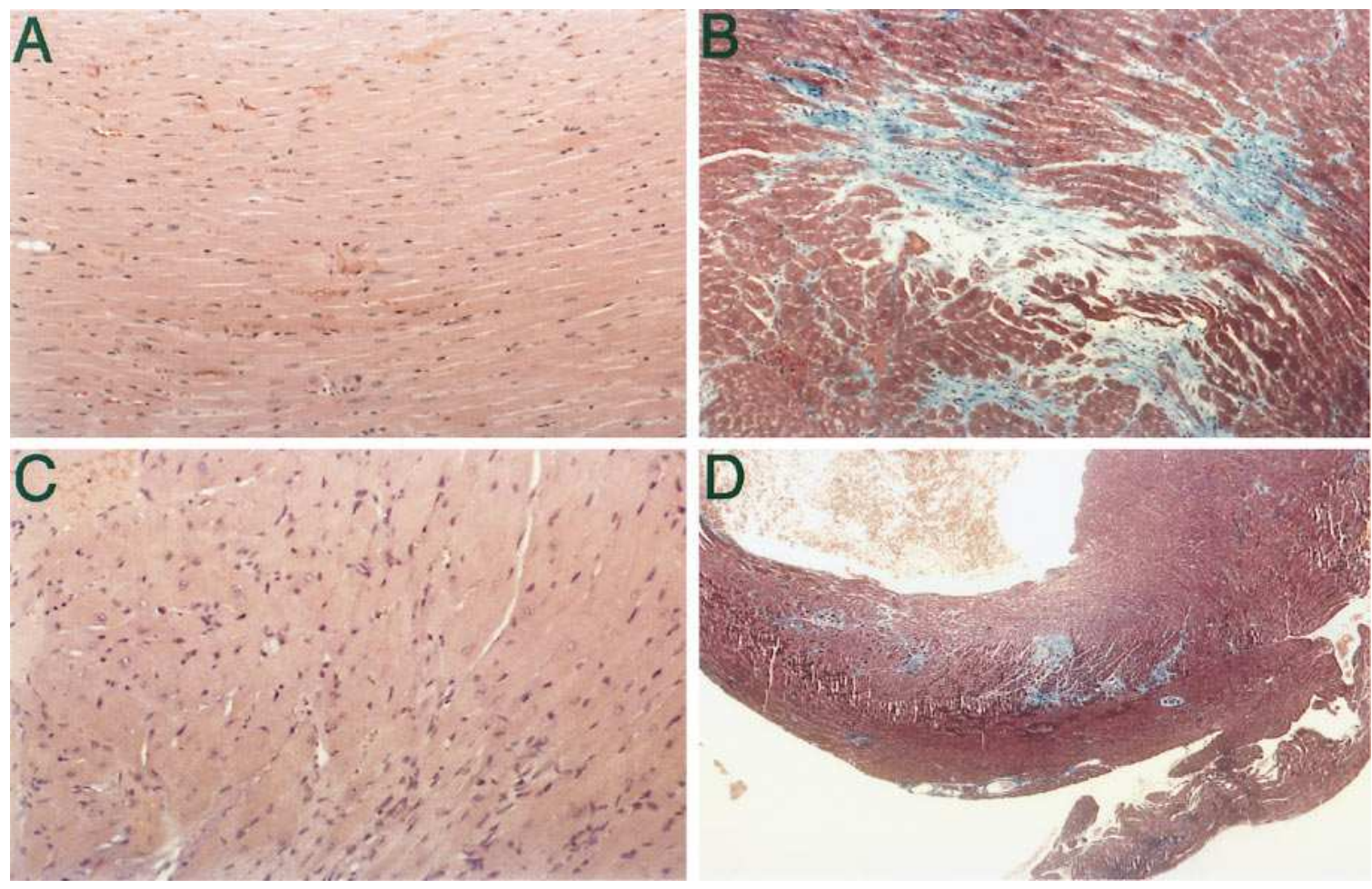

Figure 6. High magnification light microscopy of mouse hearts. Hematoxylin and eosin stained sections from wild type $(A)$ and $\alpha-M y H C^{+/-}$ mouse ventricle $(C)$. The photo in $C$ was taken adjacent to a fibrotic lesion similar to those depicted in Fig. 5. Notice the regular arrangement of myofibers in the wild type, and the relative disarray noted in the heterozygous tissue. These regions of disarray near fibrotic lesions were seen in several heterozygotes. Magnification in $A$ and $C$ is $135 \times . B$ and $D(\times 68$ and $\times 27$, respectively) photomicrographs of fibrotic lesions (blue stain) in the left ventricular free wall $(B)$ and septum $(D)$ of a heart from an $\alpha-M y H C^{+/-}$animal. 

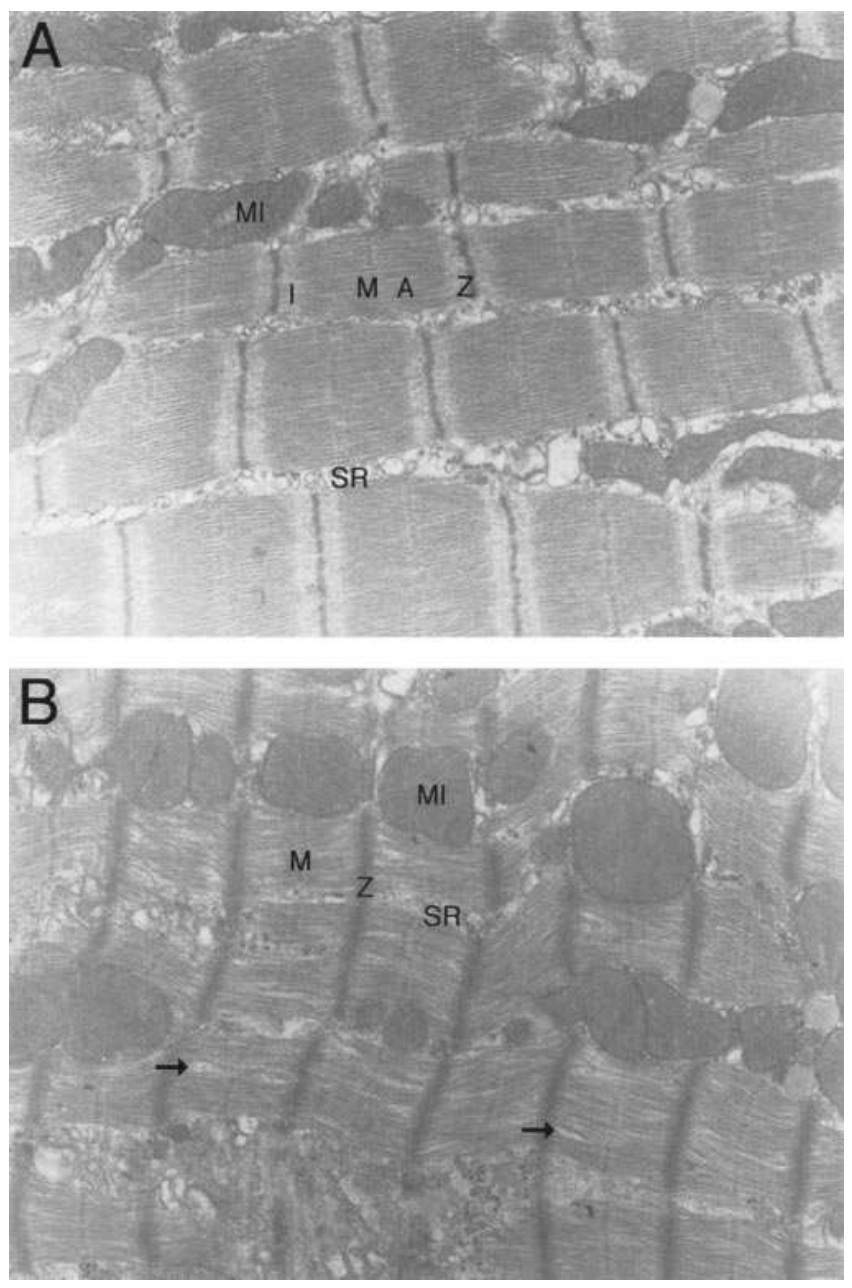

Figure 7. Electron microscopic analysis of longitudinally sectioned cardiac muscle cells from ventricular myocardium $(\times 17,000)$. $(A)$ Sections from $\alpha-M y H C^{+/+}$myocardia display the regular array of myofibrils with distinct I-bands and A-bands, in addition to well defined Z-bands and M-lines. Sarcoplasmic reticulum is well developed, and most of the mitochondria have an elongated shape. (B) A transmission electron micrograph through a transverse section of ventricular myocardium of an $\alpha-M y H C^{+/-}$mouse heart. $(\times 17,000)$. Although both samples were treated identically (see Methods), the sarcomere lengths in the heterozygote null are greatly reduced, and the M-lines are indistinct. The array of myofibrils is wavy and the myofilaments appear misaligned (arrows). The length of the sarcomeres is greatly reduced. The I-bands are indistinguishable and the A-bands occupy the entire length between Z-bands which themselves are thickened. The mitochondria in the plane of section are rounded and irregularly disturbed. A, A-bands; I, I-bands; M, M-lines; MI, mitochondria; Z, Z-bands; SR, sarcoplasmic reticulum.

fibrotic changes, two had regions of moderate myocyte hypertrophy (Fig. $6 \mathrm{C}$ ), and three appeared to have hypertrophy of the ventricular wall (right and left) associated with occlusion of the left ventricular chamber (Fig. 5, $C$ and $E$ ). No significant lesions were seen in the other three heterozygous mice.

Sarcomeric organization in $\alpha-M y H C^{+/-}$hearts. To characterize any structural consequences at the sarcomeric level of reduced MyHC synthesis, electron micrographs of longitudinal, and cross sections through the ventricular myocardia of 22-28-wk-old $\alpha-\mathrm{MyHC}^{+/-}$and $\alpha-M y H \mathrm{C}^{+/+}$mice were com- pared (Figs. 7 and 8). Examination of longitudinal sections revealed that the average sarcomeric length of $\alpha-\mathrm{MyHC}^{+/-}$myofibrils was approximately $50 \%$ of the control length (Figs. 7, $A$ and $B$, and $8, A$ and $C$ ). The A-bands of myofibrils in the $\alpha-\mathrm{MyHC}^{+/-}$hearts occupied the entire sarcomeric length, so that the I-bands could not be detected. The length of the A-band itself is reduced by approximately $75 \%$ relative to the controls. Even when compared to hypercontracted sarcomeres from wild type ventricles, the $\alpha-M y H C^{+/-}$sarcomeres are only $79 \%$ as long (Jones, W.K., and J. Robbins, unpublished results). The typical, precise interdigitation of thick and thin filaments was irregular with numerous gaps in the internal architecture of the myofibrils. Examination of cross sections revealed that while the myofibrils of the wild type myocardia contained regular hexameric arrays of thick and thin filaments, the myofibrils of the $\alpha-\mathrm{MyHC}^{+/-}$myocardia displayed numerous areas where thin filaments were absent (Fig. 8, $B$ and $D$ ), consistent with the gaps in the myofibrillar architecture noted above.

The sarcomeres of the $\alpha-M y H C^{+/-}$myocardia showed additional abnormalities including abnormally wide $\mathrm{Z}$ bands relative to controls (Fig. 7, $A$ and $B$; Fig. 8, $A$ and $C$ ). The $\mathrm{Z}$ bands contained a central core that was more dense than their outer margins. The thick and thin filaments appeared to be anchored within these widened $\mathrm{Z}$ bands. We also noted, but did
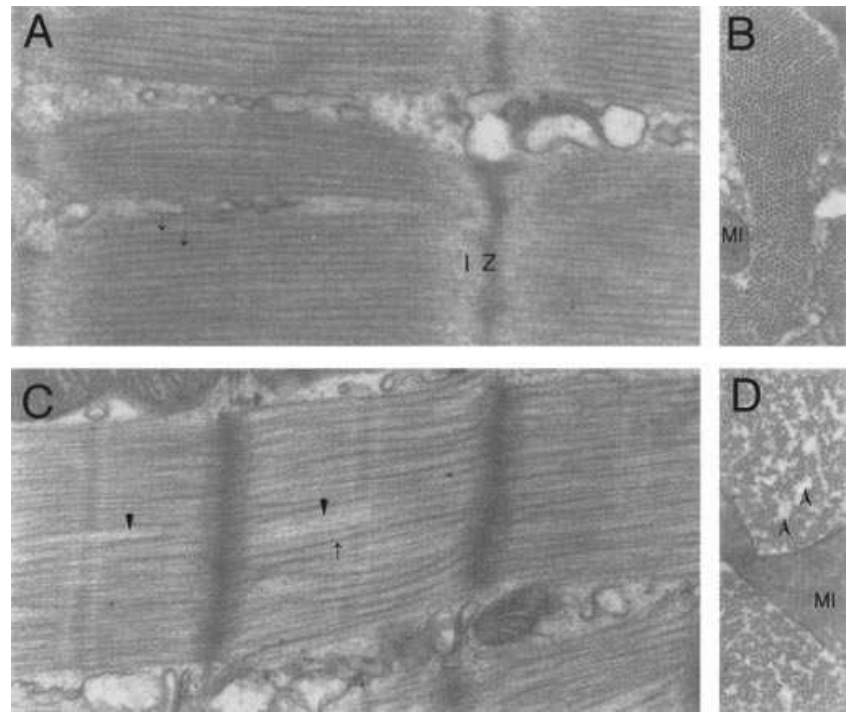

Figure 8. Electron micrographs of longitudinal $(A, C)$ and transverse, $(B, D)$ sections of ventricular cardiac myocyte cells from: $\alpha-M y H C^{+/+}$ $(A, B)$, and $\alpha-M_{y H C} C^{+-}(C, D)$ mice. Magnifications: A, C, 56,000; B, $\mathrm{D}, 28,000$. ( $A$ ) On longitudinal section, the sarcomeres from wild type myocardium have a regular organization with thick filaments extending between the I-bands (arrows indicate thick filaments that span the entire sarcomere, confirming that the section is cut transversely). (C) The sarcomeres from the heterozygotes are shortened and the thick filaments extend from Z-band to Z-band (arrows, again indicating that the sections are cut transversely). The Z-bands are thicker and their centers more dense than their margins. Some areas along the sarcomeres have no thick filaments though thin filaments are present (arrowheads). On transverse sections from wild type cardiac muscle cells $(B)$, the regular arrangement of thick and thin filaments is apparent. $(D)$ Transverse sections from the heterozygote muscle have numerous areas depleted of thick filaments, seen as cleared areas (arrowheads). MI, mitochondria. 
not quantitate differences in the shape of the mitochondria as well, the $\alpha-M y H C^{+/-}$mitochondria being rounded relative to the normally elongated mitochondria (Fig. 7, $A$ and $B$ ).

\section{Discussion}

The $\alpha-M y H C^{-}$allele is a recessive embryonic lethal resulting in a classic gene dosage effect in the adult $\alpha$ - $M y H C^{+/-}$mice. A gene dosage effect occurs when wild type and null mutant alleles are present in the heterozygous state with consequent reduction of the gene product. We detected no aberrant MyHC proteins using two antibodies with distinct MyHC specificities, indicating, though not proving, that the targeted $\alpha-M y H C$ allele is a null mutation. However, that this is an authentic null is further supported by the fact that no $\alpha-M y H C$ transcript can be detected in day 11.5 p.c. $\alpha-M y H C^{-1-}$ hearts by Northern blot analysis with four oligonucleotide probes spanning the $\alpha-M y H C$ cDNA sequence (Jones, W.K., and J. Robbins, unpublished results). Thus, the gene dosage effect is operative at both the level of transcription and translation, and is not compensated for by ectopic MyHC expression in the ventricle. The uncompensated reduction of $\alpha-M y H C$ expression results in altered cardiac function and in histopathological and ultrastructural abnormalities in some of the $\alpha-M y H C^{+/-}$ventricles.

At the physiologic level, the null allele perturbs cardiac function. The affected animals show significant reductions in parameters of contractility and relaxation of the left ventricle (Table I). The decrease in the relaxation parameters $(-d P / d t$ and $\mathrm{RT}_{1 / 2}$ ) may be a direct consequence of the mutation. However, we cannot rule out that decreased relaxation is a secondary effect of impaired contractility, since relaxation is somewhat dependent upon the extent of peak IVP. Nevertheless, the data show that mammalian left ventricular function can be severely compromised by a gene dosage effect involving a major contractile protein.

We further investigated this phenotype by analysis of the Starling function in the $\alpha-M y H C^{+/-}$hearts. Starling's law of the heart describes the increase in cardiac performance that occurs in response to increased IVP and/or volume load. The basis for this phenomenon is the well established length-tension relationship of striated muscle: as the muscle is stretched, developed tension increases to a maximum and then gradually decreases as the stretch becomes more extreme. Distention of the myocardium, which occurs with increased stroke volume, increases tension upon the cardiac myofibers and they respond with increased force generation. Relative to controls, 3/8 $\alpha-M y H C^{+/-}$hearts have essentially no left ventricular contractile response to increased load (Fig. $4 \mathrm{~B}$ ). However, the Starling response of the remaining five $\alpha$ - $M y H^{+/-}$hearts is nearly normal (the slope $\approx$ wild type) though the intercept of the Starling function curve reflects the somewhat slower relaxation time characteristic of the heterozygotes. Thus there is incomplete penetrance of a severe physiological phenotype in affected $\alpha-M y H C^{+/-}$animals.

The altered Starling relationships of the severely compromised $\alpha-M y H C^{+/-}$hearts are indicative of impaired cardiac function and we speculate that the lack of Starling function could suggest a tendency toward cardiac failure (22). Under baseline load conditions, $(250 \mathrm{mmHg} \times \mathrm{ml} / \mathrm{min}) \alpha-M y H C^{+/-}$ hearts were functioning near their maximal capacity and were unable to respond to increased cardiac workload. In addition, the increase in left ventricular diastolic pressure $(1.0 \pm 2.5$
$\mathrm{mmHg}$ versus $-8.1 \pm 2.4 \mathrm{mmHg}$ in wild type) suggests that these hearts are compromised in a manner that is consistent with impending failure. Whether the $\alpha-M y H C^{+/-}$animals will compensate for reduced cardiac function over their 30-36 mo life span, or will proceed to overt failure, remains to be seen.

Histopathological analyses likewise revealed incomplete penetrance of the phenotype in that abnormalities were noted in 5/8 $\alpha-\mathrm{MyHC}^{+/-}$hearts. Pathological findings include multifocal fibrosis of the left ventricular free wall, the intraventricular septum and the apex of the heart. Endocardial, myocardial as well as perivascular fibrotic lesions were noted. Although there is evidence that increased angiotensin converting enzyme levels are associated with myocardial fibrosis (23), we detected no increase in the steady state level of angiotensin converting enzyme transcript. Regions of cellular myocyte hypertrophy and disorganization were found in the vicinity of fibrotic lesions. Although a common feature of hypertrophic disease in humans, overall disorganization of myocytes was not prominent in the $\alpha-M y H C^{+/-}$hearts. Several of the severely affected hearts $(3 / 5)$ had thickened left ventricular free walls, septa and in some cases, right ventricles. In two cases, the lumen of the LV chamber was nearly occluded (Fig. 5). Although the five mice had some features consistent with cardiac hypertrophy, characterization of a hypertrophic phenotype must await careful morphometric analysis of a large number of affected hearts.

Ultrastructural defects were readily apparent at the TEM level in cardiac myocytes of $\alpha-M y H C^{+/-}$animals. The well defined sarcomeric pattern, a consequence of the regular interdigitation of thick and thin filaments, is overtly disrupted, and the sarcomeric length is significantly reduced. The aberrant mitochondrial orientation we observed may be a consequence of the overall disturbance in the sarcomere packing and organization. The murine cardiac sarcomeric defects are similar to those observed in the IFM of Drosophila heterozygous for the null myosin heavy chain allele $\operatorname{MHC}_{\ln } 6 B^{\operatorname{Ifm} 2(2)}(8,24)$. In the insect's IFM, thin filament assembly appeared overtly normal but the sarcomere was severely disorganized. This mutation also resulted in a noticeable disruption of the M-line, a thick filament associated structure at the sarcomeres' centers, as well as myofibrillar disarray that presented as gaps between interdigitated fibrils. These gaps presumably result from "dropout" of the thick filaments. As a result of the ultrastructural defects, the Drosophila heterozygotes exhibited muscle dysfunction and reduced flight. Thus, in both the insect's IFM and mammalian cardiac muscle, reduced MyHC gene product leads to both structural and functional deficits. We found that the MyHC protein was reduced relative to both a non-myofilament protein and to actin, a major thin filament protein, perturbing the thick:thin filament protein ratio. Our results are consistent with the hypothesis of Beall, Sepanski, and Fyrberg; that the ratio of thick and thin filament proteins is critical for proper sarcomeric assembly in muscle (8).

In Drosophila IFM, Beall and co-workers demonstrated that hemizygosity for the null MyHC allele $M H C 36 B^{\text {Ifm2(2) }}$ resulted in overall shortening of the sarcomere, and in the formation of "minisarcomeres" that were one-third the length of wild type sarcomeres (8). This mirrors our own observation that sarcomeric length is drastically reduced in the $\alpha-M y H C^{+/-}$ heterozygotes and suggests that myosin is somehow involved in sarcomeric length determination in mammals. This is consistent with models of sarcomere formation in which sarcomeres 
lengthen as muscles develop, and extends the paradigm to the vertebrate myocardium. We did note field to field variation in the severity of the above mentioned abnormalities but have described sections that are representative of over 100 fields observed for each genotype. The ultrastructure was in some cases closer to normal, while in other cases, abnormalities were even more severe relative to those described; including complete absence of the M-line, wavy and/or discontinuous $\mathrm{Z}$ bands, as well as abnormally distributed and/or swollen mitochondria.

In order to address the effect of hemizygosity for $\alpha$ - $M y H C$ upon cardiac gene expression, we quantitated the steady state transcript levels of various cardiac-specific genes that are involved in cardiac contraction and/or a hypertrophic response. We have documented an induction of transcripts previously shown (25) to be associated with a hypertrophic response to volume overload. However, as was the case for the phenotypes described above, the severity of the response was variably penetrant. One group shows a small but significant induction of ANF, while the other shows a larger induction of ANF, a significant induction of skeletal $\alpha$-actin and a significant decrease of the titin transcript. Both groups show a small but significant induction of the $\beta$ - $M y H C$ transcript (142\% of the wild type level), though the overall $\beta-M y H C$ transcript level remains less than $7 \%$ of the $\alpha-M y H C$ transcript level in the $\alpha-M y H C^{+/-}$ ventricles. ANF, $\beta$-MyHC and skeletal $\alpha$-actin are induced during cardiac hypertrophy and/or cardiomyopathy $(26,27)$. Titin is an important elastic component of the sarcomere and may play a role in sarcomerogenesis (28). Reduction in the titin:MyHC ratio as well as the expression of a unique titin isoform has been documented in studies of human cardiomyopathic heart failure, and this is associated with disarrangement and loss of filaments (filament dropout) in the sarcomere (28, 29), an observation consistent with the ultrastructural phenotype we have described.

The molecular, physiologic, and pathologic phenotypes in the $\alpha-\mathrm{MyHC}^{+/-}$animals are incompletely penetrant. Incomplete penetrance could be due to genetic or epigenetic variability of as yet undiscovered compensatory mechanisms. Because the animals studied were first and second generation hybrids of two murine strains, genetic variability is present even among siblings and incomplete penetrance may be due to variations in compensatory gene expression between the genetic backgrounds or the action of multiple alleles of modifier genes. Such a mechanism could directly affect cardiac gene expression, or indirectly affect the penetrance by variation of a physiologic response or progression of cardiac disease. Further exploration of these observations awaits the necessary backcrosses of the $\alpha-M y H C$ null allele onto different genetic backgrounds.

The current data we present do demonstrate that, in the mammalian heart, hemizygosity for the $\mathrm{MyHC}$ can have significant effects on both cardiomyocyte structure and cardiac function. What is less clear is the relationship between ultrastructure, pathology, and function. The incomplete penetrance of the molecular phenotype is consistent with the incomplete penetrance of the physiologic and pathologic phenotypes. It is possible that strain specific alleles acting as modifier genes affect the cardiac phenotype, but their involvement and identification, if they exist, remains to be discerned. It is also possible that the incomplete penetrance of the phenotypes we have characterized reflects progressive cardiac disease. The null mice offer a means to test the two alternative hypotheses; i.e., that the effect on cardiac gene expression could be either an indirect result of physiologic perturbation, or a direct result of altered $\alpha-M y H C$ expression. Studies involving transgenic expression and overexpression of mutant and wild type sarcomeric proteins in the $\alpha-M y H C$ null background should contribute to our understanding of mammalian cardiac structure and function.

\section{Acknowledgments}

We thank John Duffy for microinjections of ES cells into murine blastocysts, and Sharon Pawlowsky and Lisa Murray for expert animal husbandry.

This work was supported by National Institutes of Health grants HL-46826, HL-41496, HL-22619, and HL-52318 to J. Robbins and American Heart Association grant SW-95-22-I to W.K. Jones.

\section{References}

1. Lyons, G.E., S. Schiaffino, D. Sassoon, P. Barton, and M. Buckingham. 1990. Developmental regulation of myosin gene expression in mouse cardiac muscle. J. Cell Biol. 111:2427-2436.

2. Ng, W.A., I.L. Grupp, A. Subramaniam, and J. Robbins. 1991. Cardiac myosin heavy chain mRNA expression and myocardial function in the mouse heart. Circ. Res. 68:1742-1750.

3. Izumo, S., B. Nadal-Ginard, and V. Mahdavi. 1986. All members of the MHC multigene family respond to thyroid hormone in a highly tissue-specific manner. Science (Wash. DC). 231:597-600.

4. Seidman, C.E., and J.G. Seidman. 1991. Mutations in cardiac myosin heavy chain genes cause familial hypertrophic cardiomyopathy. Mol. Biol. Med. 8:159-166.

5. Lankford, E.B., N.D. Epstein, L. Fananapazir, and H.L. Sweeney. 1995 Abnormal contractile properties of muscle fibers expressing beta-myosin heavy chain gene mutations in patients with hypertrophic cardiomyopathy. J. Clin. Invest. 95:1409-1414.

6. Straceski, A., C.E. Geisterfer-Lowrance, C.E. Seidman, J.G. Seidman, and L. Leinwand. 1994. Functional analysis of myosin missense mutations in familial hypertrophic cardiomyopathy. Proc. Natl. Acad. Sci. USA. 91:589-593.

7. Geisterfer-Lowrance, A.A.T., M. Christe, D.A. Conner, J.S. Ingwall, F.J. Schoen, C.E. Seidman, and J.G. Seidman. 1996. A mouse model of familial hypertrophic cardiomyopathy. Science (Wash. DC). 272:731-734.

8. Beall, C.J., M.A. Sepanski, and E.A. Fyrberg. 1989. Genetic dissection of Drosophila myofibril formation: effects of actin and myosin heavy chain null alleles. Genes Dev. 3:131-140.

9. Bernstein, S.I., P.T. O’Donnell, and R.M. Cripps. 1993. Molecular genetic analysis of muscle development, structure, and function in Drosophila. Int. Rev. Cytol. 143:63-152.

10. Brown, D.G., V.N. Warren, P. Pahlsson, and S.J. Kimber. 1993. Carbohydrate antigen expression in murine embryonic stem cells and embryos, I. Histochem. J. 25:452-463.

11. Kimber, S.J., D.G. Brown, P. Pahlsson, B. Nilsson, D.G. Brown, V. N. Warren, P. Pahlsson, S.J. Kimber, S. Sawai, A. Shimono, et al. 1993. Carbohydrate antigen expression in murine embryonic stem cells and embryos, II. Histochem. J. 25:628-641.

12. Gossler, A., T.C. Doetschman, R. Korn, E. Serfling, and R. Kemler. 1986. Transgenesis by means of blastocyst-derived embryonic stem cell lines. Proc. Natl. Acad. Sci. USA. 83:9065-9069.

13. Chan, S.Y., and M.J. Evans. 1991. In situ freezing of embryonic stem cells in multiwell plates. Trends Genet. 7:76.

14. Robbins, J., J. Gulick, A. Sánchez, P. Howles, and T. Doetschman. 1990 Mouse embryonic stem cells express the cardiac myosin heavy chain genes during development in vitro. J. Biol. Chem. 265:11905-11909.

15. Sánchez, A., W.K. Jones, J. Gulick, T.C. Doetschman, and J. Robbins 1991. Myosin heavy chain gene expression in mouse embryoid bodies. J. Biol. Chem. 266:22419-22426.

16. Subramaniam, A., W.K. Jones, J. Gulick, S. Wert, J. Neumann, and J. Robbins. 1991. Tissue-specific regulation of the $\alpha$-myosin heavy chain gene promoter in transgenic mice. J. Biol. Chem. 266:24613-24620.

17. Rudnicki, M.A., G. Jackowski, L. Saggin, and M.W. McBurney. 1990 Actin and myosin expression during development of cardiac muscle from cultured embryonal carcinoma cells. Dev. Biol. 138:348-358.

18. Grupp, I.L., A. Subramaniam, T.E. Hewett, J. Robbins, and G. Grupp. 1993. Comparison of normal, hypodynamic, and hyperdynamic mouse hearts using isolated work-performing heart preparations. Am. J. Physiol. 265:H14011411.

19. Hewett, T.E., I.L. Grupp, G. Grupp, and J. Robbins. 1994. Alpha-skele- 
tal actin is associated with increased contractility in the mouse heart. Circ. Res. 74:740-746.

20. Daniel, Wayne W. 1987. Biostatistics: A Foundation for Analysis in the Health Sciences. John Wiley and Sons, Inc. Third ed. 1983. 276-289. New York, NY.

21. Bowerman, B.L., R.T. O'Connell, and D.A. Dickey. 1986. Linear Statistical Models: an Applied Approach. PWS/Duxbury Press, Boston, MA. 343351.

22. Schwinger, R.H., M. Bohm, A. Koch, U. Schmidt, I. Morano, H.J. Eissner, P. Uberfuhr, B. Reichart, and E. Erdmann. 1994. The failing human heart is unable to use the Frank-Starling mechanism. Circ. Res. 74:959-969.

23. Sun, Y., and K.T. Weber. 1996. Angiotensin-converting enzyme and wound healing in diverse tissues of the rat. J. Lab. Clin. Med. 127:94-101.

24. Chun, M., and S. Falkenthal. 1988. Ifm(2)2 is a myosin heavy chain allele that disrupts myofibrillar assembly only in the indirect flight muscle of Drosophila melanogaster. J. Cell. Biol. 107:2613-2621.
25. Boluy, M.O., L.O. Neill, A.L. Meredith, O.H.L. Bing, W.W. Brooks, C.H. Conrad, M.T. Crow, and E.G. Lakatta. 1994. Alterations in cardiac gene expression during the transition from stable hypertrophy to heart failure. Circ. Res. 75:23-32.

26. Schwartz, K., L. Carrier, C. Chassagne, C. Wisnewsky, and K.R. Boheler. 1992. Regulation of myosin heavy chain and actin isogenes during cardiac growth and hypertrophy. Symp. Soc. Exp. Biol. 46:265-272.

27. Schwartz, K., C. Chassagne, and K.R. Boheler. 1993. The molecular biology of heart failure. J. Am. Coll. Cardiol. 22:(4 Supp. A), 30A.

28. Hein, S., D. Scholz, N. Fujitani, H. Rennollet, T. Brand, A. Friedl, and J. Schaper. 1994. Altered expression of titin and contractile proteins in failing human myocardium. J. Mol. Cell Card. 26:1291-1306.

29. Morano, I., K. Hadicke, S. Grom, A. Kock, R.H. Schwinger, M. Bohm, S. Bartel, E. Erdmann, and E.G. Krause. 1994. Titin, myosin light chains and C-protein in the developing and failing human heart. J. Mol. Cell Cardiol. 26: 361-368. 